\title{
Agricultores Consomem Frutas, Verduras e Legumes? Bases para Ações Educativas 1
}

\author{
Maria Cristina Faber Boog ${ }^{2}$; Maria da Conceição Pereira da Fonseca ${ }^{3}$; Hayda Josiane \\ Alves $^{4}$; Cristiane Ramos Voorpostel ${ }^{5}$
}

\begin{abstract}
Avaliou-se o consumo de frutas, verduras e legumes (FVL) por população de fruticultores, relacionando-o com trabalho, disponibilidade local desses produtos e produção para auto-consumo, com finalidade de subsidiar programas educativos. O delineamento consistiu em estudo de corte transversal, realizado entre famílias de alunos de escola de zona rural do município de Valinhos/SP - Brasil. Por meio de entrevista coletou-se dados socioeconômicos, de consumo alimentar e dados subjetivos relativos à percepção dos sujeitos sobre suas próprias práticas. A população estudada compreendeu 79 famílias, totalizando 420 pessoas; $53,0 \%$ das famílias trabalhavam na terra, 70,5\% possuíam horta e 80,0\% árvores frutíferas ao redor do domicílio; $85 \%$ referiram consumir verduras, $83 \%$ legumes e $91 \%$ frutas, considerando esses alimentos pertinentes ao seu padrão alimentar. Entretanto, no dia alimentar, 59,5\% declararam não consumir frutas, $70,9 \%$ não consumiram verduras e 53,2\% nenhum legume. Conclui-se que o acesso à terra não é um fator que por si só favoreça produção e consumo de FVL. Os motivos que levam ao baixo consumo relacionam-se a preferências, papel da mulher no trabalho agrícola como fator limitante do tempo destinado ao preparo das refeições, e relações de trabalho. Programas educativos devem ser pautados nos condicionantes objetivos e subjetivos da alimentação, incluindo estratégias para emancipação e aumento do controle sobre a vida.
\end{abstract}

Palavras-chave: segurança alimentar e nutricional; educação alimentar e nutricional; consumo de alimentos; nutrição comunitária.

\section{Do Farmers Eat Fruits, Greens and Vegetables? Basis for Educational Actions}

In order to guide educational programs, the consumption of fruits, greens and vegetables (FGV) was surveyed among fruit and vegetable farmers in order to assess the farmers families' adherence to healthy feeding as a result of the immediate access to these produce for their own consumption. A cross-sectional study was carried out comprising families of schoolchildren living in a rural area of the city of Valinhos, southeastern Brazil, in 2006. Through interviews the students supplied the socioeconomic data, food consumption information and their subjective perception of their own food consumption practices. The studied population included 79 families comprising 420 individuals; $53.0 \%$ of families worked the land, $70.5 \%$ had vegetable gardens, and $80.0 \%$ had fruit trees surrounding their homes; $85 \%$ were consumers of greens, $83 \%$ of vegetables, and $91 \%$ of fruits, and considered these food items as part of their food habits. However, in the 24-hour recall, $59.5 \%$ did not consume any fruits, $70.9 \%$ did not consume any greens, and 53.2\% consumed

\footnotetext{
${ }^{1}$ Apresentado no I World Congress of Public Health Nutrition. Barcelona, Espanha, 28-30 de Setembro de 2006.

${ }^{2}$ Universidade Estadual de Campinas

${ }^{3}$ Universidade Federal da Bahia

${ }^{4}$ Universidade Federal do Rio de Janeiro

${ }^{5}$ Pontifícia Universidade Católica de Campinas - SP
} 
no vegetables. The conclusion is that access to the land is not a factor that by itself would promote the consumption of FGV. The reasons leading to such low consumption refer to personal preferences, women's role in rural activities, limited time for food preparation and labor relations. Educational programs should be guided by objective and subjective conditioning factors of food habits, and include strategies leading to the self determination and improvement of the control of people's lives.

Index-terms: food security; nutrition education: food-consumption; community nutrition.

\section{Introdução}

Recomendações emanadas da $57^{\mathrm{a}}$. Assembléia Mundial da Saúde $^{1}$ exortam governos e outras partes interessadas a criar entornos que motivem e proporcionem meios para que pessoas, famílias e comunidades adotem comportamentos alimentares saudáveis. A eficácia das ações de promoção da alimentação saudável depende do conhecimento sobre o consumo e da apreensão do contexto em que ele ocorre, pois é necessário compreender as razões subjacentes às práticas alimentares, para que se possa propor ações concebidas a partir do conhecimento delas e da subjetividade que as permeia $^{2}$. No caso da alimentação não basta quantificar a ingestão de alimentos e/ou nutrientes, mas é relevante compreender aspectos da organização doméstica, relativos ao suprimento de gêneros e preparo das refeições, bem como as representações sociais acerca do fato alimentar, pois estas constituem um corpo organizado de conhecimentos que explica o modo de prover o próprio sustento e de utilizar os alimentos disponíveis com determinados sentidos, gerados a partir dos significados que eles têm em uma dada cultura $^{3}$.

A problemática que envolve o consumo de frutas, verduras e legumes (FVL) vem sendo estudada por vários autores ${ }^{4,5,6}$. Estudos realizados no Brasil apontam a baixa ingestão de FVL, especialmente entre jovens, do sexo masculino, de áreas rurais, com baixa escolaridade e renda ${ }^{7,8,9}$, e recomendam o incentivo ao consumo desses alimentos. Esses estudos visaram conhecer níveis de consumo, porém não explicam as razões do baixo consumo, e, especialmente, configura-se como questão instigante, compreender as razões pelas quais grupos populacionais que, tendo sua vida imersa na produção agrícola, dela pouco se utilizam para o próprio sustento.

A pesquisa objeto do presente artigo constitui parte de um projeto composto por quatro pesquisas e uma intervenção educativa cujo propósito geral foi desenvolver um programa educativo de promoção de alimentação saudável, concebido a partir de diagnóstico de padrão de consumo e da concepção de nutrição comunitária ${ }^{10,11}$, tomada como filosofia de intervenção. A nutrição comunitária é uma abordagem por meio da qual se procura desenvolver intervenções integradas, concebidas a partir do diagnóstico da realidade social e cultural, dos usos e costumes, reconhecendo a variedade de circunstâncias e situações possíveis, condicionantes do padrão alimentar de uma população residente em território delimitado.

A escolha do local para desenvolvimento do projeto recaiu sobre uma área rural, na qual existia uma escola freqüentada por filhos de agricultores moradores do bairro, o que possibilitaria que a intervenção educativa fosse, posteriormente, desenvolvida a partir desta escola.

A presente pesquisa foi proposta, tomando como objeto de estudo a alimentação de famílias de alunos de uma escola rural. O objetivo foi avaliar o consumo de FVL em uma comunidade agrícola, relacionando-o com o trabalho, a disponibilidade local desses produtos e a possibilidade de produção para auto-consumo.

\section{Método}

$\mathrm{Na}$ busca de referencial teórico para realizar um diagnóstico abrangente, optou-se pela teoria do espaço social alimentar de Poulain e Proença ${ }^{12}$, por considerá-la suficientemente ampla para abarcar não 
apenas questões inerentes ao consumo de alimentos, mas também outras, de natureza objetiva e subjetiva, explicativas do comportamento alimentar. O conceito de espaço social alimentar, adotado por esses autores, considera a alimentação um fenômeno complexo, que se define, por um lado, como fato social, parcialmente determinado por mecanismos sociais, mas também como objeto biológico e psicológico. Na Figura 1, apresenta-se uma adaptação ao presente estudo do esquema original de Poulain e Proença, mostrando diferentes níveis do fato alimentar, que foram analisados neste estudo. A abcissa indica uma gradação que vai de um fato passível de constatação objetiva (esquerda) às descrições/opiniões dos mesmos permeados pela subjetividade dos sujeitos (direita). A ordenada parte das práticas alimentares objetivas (parte inferior), às representações dessas práticas conforme expressadas pelos sujeitos (parte superior). O consumo alimentar está na área de práticas reconstruídas que são descritas pelos sujeitos, em entrevistas, nas quais se pede a eles que revivam, através da memória, o seu consumo alimentar nas últimas 24 horas, e de práticas declaradas, quando se indaga a respeito de práticas não circunscritas a um determinado tempo recente. Foi realizado inquérito socioeconômico e de consumo alimentar empregando o recordatório de 24horas (R24h) e freqüência de consumo de FVL. Os dados foram registrados em formulário pré-testado, preenchido em entrevista com donas de casa, mães de crianças que freqüentavam a escola. $\mathrm{O}$ almoço e o jantar foram avaliados como completos ou incompletos segundo a presença concomitante ou não de alimentos construtores, energéticos e reguladores e o desjejum foi avaliado como completo (contendo alimentos dos três grupos), incompleto ou padrão, sendo este último composto por leite acompanhado por pão ou similar $^{13}$. Neste instrumento foram incluídas questões relativas aos condicionantes do consumo - disponibilidade local e consumo de produção própria, e questões relativas à percepção dos sujeitos sobre seu consumo de alimentos.

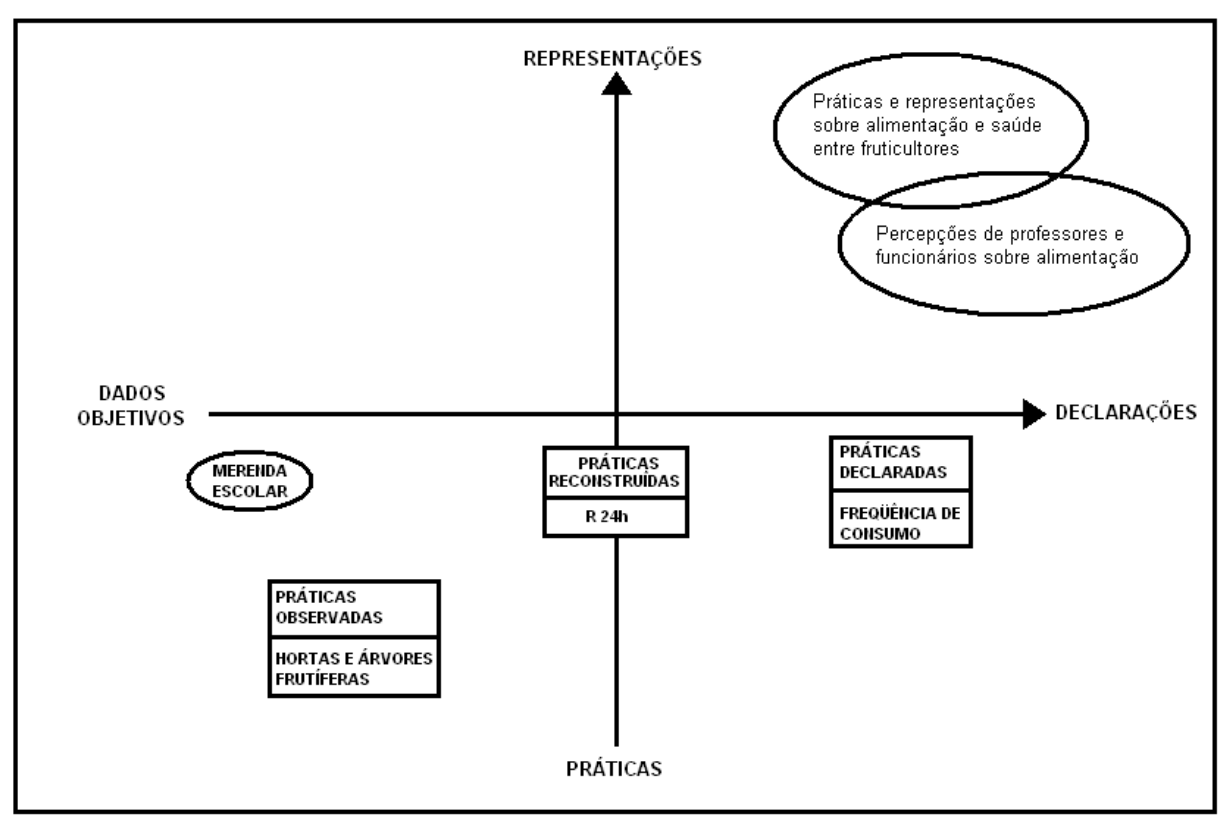

Figura1: Níveis de análise do comportamento alimentar (adaptado de Poulain e Proença ${ }^{12}$ ). 
Como se tratou de estudo de consumo que tinha por finalidade subsidiar ações de educação alimentar e nutricional e promoção da saúde, era relevante um dado qualitativo ou quantitativo que pudesse ser devolvido à comunidade e compreendido pela mesma. O foco do estudo não foi sobre a ingestão de nutrientes, mas sobre o consumo de alimentos, a percepção dos sujeitos sobre esse consumo e fatores condicionantes das práticas alimentares. Por esse motivo não se pretendeu mensurar e nem estimar a quantidade (em gramas) consumida, mas apenas avaliar a presença ou ausência, especialmente de FVL e conhecer a percepção dos entrevistados sobre o seu consumo.

O estudo foi realizado com famílias de alunos de uma Escola Municipal de Ensino Fundamental localizada em zona rural do Município de Valinhos, Estado de São Paulo Brasil. O Município tinha uma população estimada, para 2006, em 94.124 habitantes, distribuídos em $149 \mathrm{~km}^{2}$, com um índice de desenvolvimento humano de 0,842. Este estudo constituiu parte do projeto "Promoção da saúde, segurança alimentar e nutrição: a contribuição da educação nutricional" $(\mathrm{CNPq}$ 402078/2005-5).

A escolha da escola foi definida tomando como base o fato de atender a uma comunidade de agricultores e também pela disponibilidade em receber o estudo, portanto, a amostra foi por conveniência. Pretendia-se que a pesquisa abrangesse a totalidade das famílias de alunos dessa escola, contudo, por dificuldades na coleta de dados, atingiu-se $78,7 \%$ desse universo. Não foi possível a realização das entrevistas com as demais famílias por dificuldade de localização do domicílio, ou ausência do responsável em três tentativas de abordagem. Desse modo, para este estudo não foi efetuado cálculo amostral mais complexo. As informações sobre os sujeitos foram obtidas na escola. A Tabela 1 traz o número de alunos da escola, matriculados por séries, e o número de entrevistas realizadas.

Tabela 1. Entrevistas realizadas nos domicílios dos alunos da escola Municipal Carolina Sigrist (Valinhos-SP, 2006).

\begin{tabular}{ccccc}
\hline \multirow{2}{*}{ Séries } & \multicolumn{3}{c}{ Número de matriculados } & \multicolumn{2}{c}{ Entrevistas realizadas } \\
\cline { 2 - 5 } & $\mathrm{N}$ & $\%$ & $\mathrm{~N}$ & $\%$ \\
\hline Pré-escola & 14 & 9,0 & 11 & 7,1 \\
Infantil II & 6 & 3,9 & 5 & 3,2 \\
$1^{\mathrm{a}}$ & 22 & 14,2 & 20 & 12,9 \\
$2^{\mathrm{a}}$ & 16 & 10,3 & 14 & 9,0 \\
$3^{\mathrm{a}}$ & 17 & 11,0 & 11 & 7,1 \\
$4^{\mathrm{a}}$ & 22 & 14,2 & 21 & 13,5 \\
$5^{\mathrm{a}}$ & 17 & 11,0 & 9 & 5,8 \\
$6^{\mathrm{a}}$ & 21 & 13,5 & 18 & 11,6 \\
$7^{\mathrm{a}}$ & 13 & 8,4 & 12 & 7,7 \\
Outros (não localizados nas séries) & 7 & 4,5 & 1 & 0,6 \\
\hline Total & 155 & 100,0 & 122 & 78,7 \\
\hline
\end{tabular}


Para cálculo da renda familiar mensal per-capita foram somados os ingressos mensais da família e depois o total foi dividido pelo número de membros na família. Não se considerou neste cálculo o ganho no final do ano agrícola.

$\mathrm{O}$ método empregado caracterizou-se como estudo de corte transversal, desenvolvido com famílias de alunos que freqüentavam uma escola municipal localizada em bairro rural, cercada por plantações de figo, goiaba, uva e morango. As técnicas de coleta de dados foram entrevista sobre consumo de alimentos e observação do domicílio, do terreno e plantações. Antes de iniciar a coleta de dados, uma das pesquisadoras frequientou a comunidade $\mathrm{e}$ outra a escola ao longo de um ano, comparecendo a esses locais uma vez por semana, estabelecendo assim relacionamentos de confiança na comunidade, de forma que a entrevista não foi apenas uma enquete para obtenção de informações, mas efetivamente um diálogo que possibilitou aos entrevistadores, o acesso a aspectos inerentes à subjetividade dos sujeitos de interesse para o estudo.

Foi realizada também uma apresentação dos pesquisadores envolvidos durante uma reunião da Pastoral da Criança, e foram enviados bilhetes às famílias, informando sobre a visita dos entrevistadores.

Os dados quantitativos foram organizados e analisados no programa MINITAB 14, S-PLUS, STATA 8, teste exato de Fischer, teste T e teste de Qui-Quadrado, sendo que o nível de significância adotado foi de $5 \%$.

Todos os sujeitos assinaram previamente termo de consentimento, conforme preconizado pela Resolução MS 196/97. O projeto foi aprovado por Comitê de Ética em Pesquisa da Faculdade de Ciências Médicas da Universidade Estadual de Campinas sob protocolo 242/2005.

\section{Resultados}

\section{Caracterização da população estudada}

A população estudada compreendeu 79 famílias, residentes em zona rural, totalizando 420 pessoas, sendo 4 a 6 o número de pessoas por domicílio. Do total de famílias, 58\% trabalhavam na agricultura, sendo $48,1 \%$ do total como parceiras, em regime de meação, na produção agrícola de frutas. Quando a família trabalha no regime de parceria todos os seus membros trabalham juntos no mesmo sítio. Os que não eram agricultores trabalhavam na cidade, mas também moravam em sítios, o que conferiu ao universo de estudo uma homogeneidade em relação ao estilo de vida.

As famílias eram compostas por pessoas jovens, com distribuição bimodal da idade: entre 0 e 20 anos (média 9 anos) e mais de 21 anos (média 36 anos), observando-se reduzida presença de idosos entre as famílias estudadas (1,19\%). O nível de escolaridade era baixo, pois $73,2 \%$ das pessoas maiores de 15 anos apresentavam ensino fundamental incompleto ou menos, com índice de analfabetismo de $7,4 \%$, superior à taxa de analfabetismo entre maiores de 10 anos na região sudeste, que era de $6 \%$ no biênio 2005/2006 ${ }^{14}$.

A renda média familiar per-capita (RMFPC) dos agricultores era de R $\$ 169,00$ (U\$ 79,66) variando de $\mathrm{R} \$ 25,00(\mathrm{U} \$ 11,78)$ a $\mathrm{R} \$ 500,00$ (U\$235,67). A dos não agricultores era de $\mathrm{R} \$ 196,00$ (U\$92,38), variando de $\mathrm{R} \$$ 53,00 (U\$24,98) a $\mathrm{R} \$ 825,00$ (U\$388,86). Mais da metade das famílias vivia com menos de 0,5 salário mínimo familiar mensal percapita. Como a renda pela venda das frutas só é obtida ao final do período de cultivo, geralmente um ano, o contrato de parceria prevê que o trabalhador receba, mensalmente, uma quantia referida como "adiantamento", que ele usa para as despesas do mês. Os entrevistados relataram que nesse acerto de contas final, são feitos os descontos referentes aos adiantamentos e outras despesas com a produção, de forma que às vezes o parceiro recebe, outras não recebe nada, e às vezes é informado de que ficou devendo. Quando se faz o acerto de contas, as famílias adquirem bens duráveis, especialmente eletrodomésticos (televisão, aparelho de som, DVD) e carros usados, fora de linha, o que explica que 55,6\% das famílias de parceiros possuam carro, contra $39,0 \%$ das demais famílias, diferença 
que não foi significativa ao nível de 95\% ( $\mathrm{p}=$ 0,174). Esse montante recebido no acerto de contas não é gasto com alimentação, não influenciando, portanto, a qualidade da mesma. As famílias não sabem quanto vão receber no final do ano agrícola. Mas é importante ressaltar que esse rendimento não influencia o consumo de alimentos, uma vez que a manutenção da família se dá por intermédio dos adiantamentos que têm um valor fixo e baixo. Além disso, a renda obtida no acerto de contas é utilizada apenas para a aquisição de bens duráveis, representativos da recompensa concreta e duradoura pelo trabalho realizado.

\section{Práticas de produção de FVL para auto- consumo}

Com a finalidade de conhecer a disponibilidade de FVL, perguntou-se e também se observou as práticas de produção para auto-consumo. A maioria das famílias possuía, no terreno onde morava, uma pequena horta $(70,5 \%)$ e árvores frutíferas $(80,0 \%)$, destinadas a consumo próprio, além da plantação em grande escala relativa ao contrato de meação. Quando se perguntava o que era plantado na horta, o percentual era menor, pois nenhum tipo específico de hortaliça foi mencionado por, pelo menos, metade dos entrevistados. A cebolinha foi a mais freqüente, encontrada em $36,7 \%$ das casas, seguida pela alface $(32,9 \%)$, couve
$(30,4 \%)$ e mandioca $(13,9 \%)$. Entre as árvores, a mais freqüente foi mangueira $(39,2 \%)$, seguida pelo abacateiro $(36,7 \%)$, bananeira $(30,4 \%)$, jabuticabeira e limoeiro $(21,5 \%)$ e laranjeira $(19,0 \%)$.

Os proprietários não incentivam os meeiros a cultivar hortas, segundo estes, por se gastar mais água e também devido ao tempo despendido com uma atividade não produtiva do ponto de vista econômico. Os meeiros não se sentem motivados a plantar porque não são proprietários da terra $\mathrm{e}$ mudam-se freqüentemente de um sítio para outro, não tendo, portanto, interesse em plantar um alimento que talvez não cheguem a colher para seu próprio consumo.

\section{Práticas de consumo de FVL}

Quando solicitados a declarar se consumiam FVL, os percentuais de respostas afirmativas foram elevados: $91,0 \%, 85,0 \%$ e $83,0 \%$, respectivamente, para esses grupos de alimentos. No entanto, a análise do consumo obtida por meio do R24h, mostrou que 59,5\% não referiram consumo de frutas, $70,9 \%$ de verduras e $53,2 \%$ de legumes e apenas 3,8\%, $2,5 \%$ e $3,8 \%$ consumiram pelo menos duas vezes no dia esses alimentos (Tabela 2). Com base na categorização dos chefes das famílias como parceiros e assalariados não foram observadas diferenças significativas ao nível de $95 \%$ de confiança $(p=0,184)$ nas declarações desses dois grupos de famílias.

Tabela 2. Distribuição percentual dos sujeitos segundo o número de tomadas alimentares de FVL no dia alimentar (Valinhos-SP, 2006).

\begin{tabular}{lcccc}
\hline \multirow{2}{*}{ Alimentos } & \multicolumn{4}{c}{ Tomadas alimentares } \\
\cline { 2 - 5 } & $\mathbf{0}$ & $\mathbf{1}$ & $\mathbf{2}$ & $\mathbf{3}$ \\
\hline Frutas e sucos naturais & 59,5 & 32,9 & 3,8 & 3,8 \\
Verduras & 70,9 & 26,6 & 2,5 & - \\
Legumes & 53,2 & 41,8 & 3,8 & 1,3 \\
\hline
\end{tabular}


No dia alimentar da pesquisa, $12,6 \%$ referiram ter consumido banana e 5,1\%, goiaba. O consumo de verduras foi relatado por $29,1 \%$ dos entrevistados e o de legumes por $46,9 \%$, sendo o tomate o legume mais consumido, apesar deste ser comprado. $\mathrm{Na}$ figura 2 é apresentado o percentual com que figura o consumo de vários tipos de FVL no R24 e nas alternativas "freqüentemente" e "de vez em quando". Este gráfico possibilita perceber a discrepância entre o que se declara consumir e as práticas reconstruídas no R24h, que refletem com mais fidedignidade o consumo no dia da pesquisa.

Um exemplo que ilustra a não correspondência entre disponibilidade de um produto e seu consumo é o caso do abacate. A coleta de dados foi realizada no mês de abril, quando os abacateiros já se encontravam em período de produção e, embora esta tenha sido a segunda árvore frutífera mais presente nos sítios, em $36,7 \%$ deles, o abacate foi a sexta fruta na ordem de consumo, tendo sido citada por apenas $5,5 \%$ dos entrevistados.
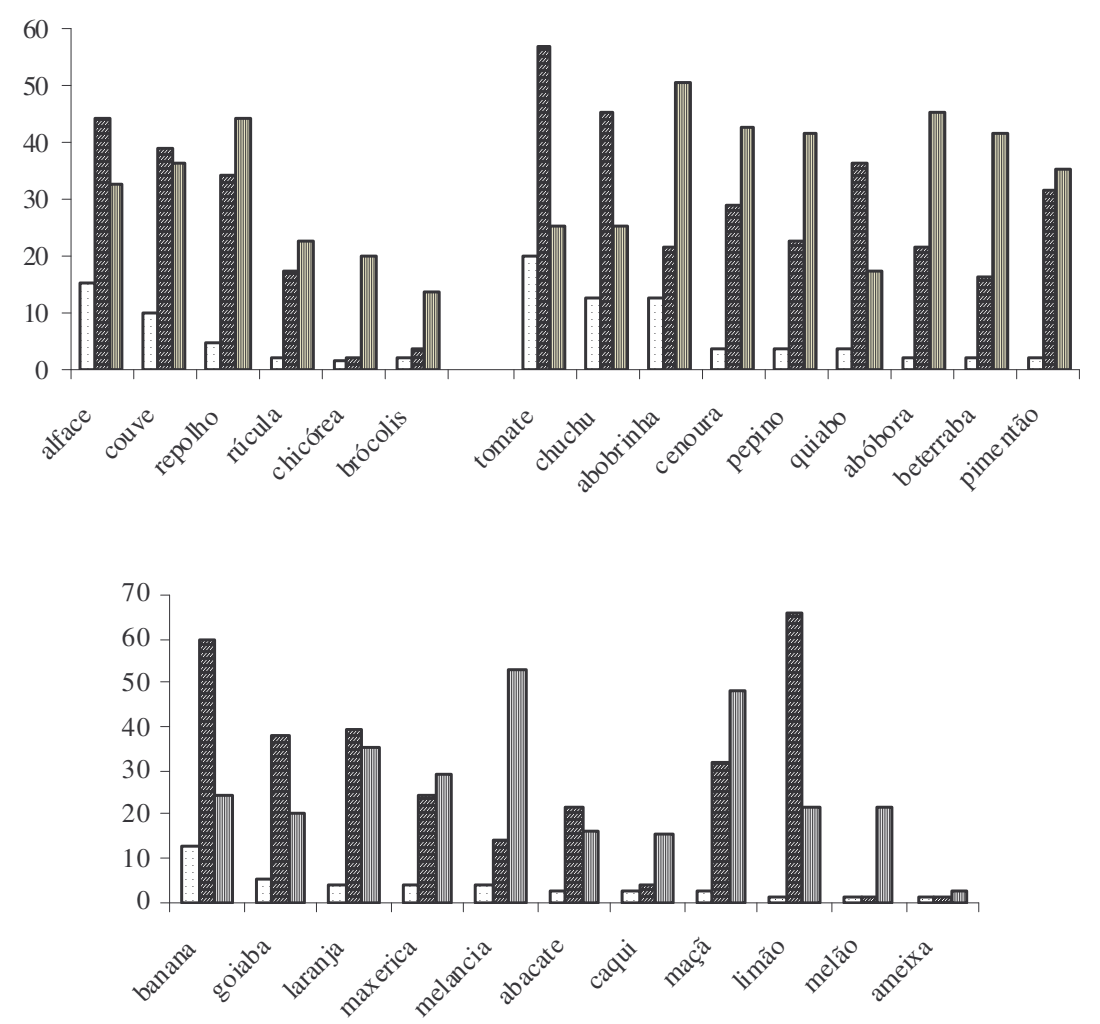

R24h Freqüentemente 四De vez em quando

Figura 2 - Comparação entre percentuais de consumo de frutas, verduras e legumes no R24h e na avaliação por freqüência. (Valinhos-SP, 2006)

Entre os temperos, de acordo com as declarações dos entrevistados, são empregados no preparo de alimentos, a cebola e o alho que foram citados por $86,1 \%$ e $72,2 \%$ dos entrevistados, seguidos pela cebolinha $(64,6 \%)$, pimenta $(34,2 \%)$ e salsinha $(27,8 \%)$.

Uma estratégia importante para obtenção de alimentos é a doação entre vizinhos de gêneros produzidos nos próprios sítios, prática comum entre as famílias.

Quando perguntados acerca de sua percepção sobre o consumo de alguns alimentos, ou seja, se a quantidade consumida era, na opinião do entrevistado, alta (boa, suficiente) ou pouca (insuficiente), observouse semelhança na auto-avaliação da maioria 
dos alimentos entre famílias que se encontravam no percentil de renda baixo e no percentil de renda alto, sendo que exceções foram observadas apenas em relação a carnes e refrigerantes. Daqueles que se encontravam no percentil de renda baixo, 35\% referiram consumo bom de carnes, e $45 \%$ insuficiente, enquanto $60 \%$ de entrevistados do percentil de renda alto referiram um consumo bom, e 15\% pouco. Em relação ao consumo de refrigerante, $42,3 \%$ dos entrevistados do percentil de renda alto referiram consumir bastante, enquanto apenas $3,4 \%$ dos entrevistados do percentil de renda baixo assim se posicionaram. Essas diferenças são estatisticamente significativas a um nível de 95\% de confiança, sendo $\mathrm{p}=0,037$ no caso das carnes e $p=0,001$ no caso dos refrigerantes.

Em relação à escolaridade materna, não foram observadas diferenças significativas no consumo de verduras, legumes e frutas entre famílias cujas mães não concluíram o ensino fundamental e famílias cujas mães concluíram o ensino fundamental ou níveis mais avançados.

\section{Qualidade das refeições}

A análise qualitativa das refeições mostrou que a maioria delas é incompleta (Tabela 3), e isso se deve, principalmente, à ausência de verduras e legumes. O percentual de entrevistados que consumiu uma ou mais porções desses alimentos foi de $40,5 \%$ para frutas, $29,1 \%$ para verduras e $46.9 \%$ para legumes.

Os assalariados apresentaram proporção de almoços completos ligeiramente maior do que parceiros, embora a diferença não seja significativa $(p=0,251)$. Esta se deve, provavelmente, ao fato dos assalariados almoçarem nos seus empregos. A proporção de jantares incompletos é maior para os parceiros do que para os assalariados, sendo que essa diferença foi significativa $(\mathrm{p}=$ 0,012).

Mulheres que trabalham no regime de parceria dispõem de pouco tempo, apenas uma hora, para preparar a refeição e almoçar, o que limita o tempo disponível para preparo da refeição. Este fato foi declarado pelos entrevistados e observado pelos entrevistadores.

Em relação ao desjejum, a maior freqüência foi observada na categoria "somente café", consumo referido por $38 \%$ dos entrevistados, seguida por "desjejum incompleto" (36,7\%), isto é, composto por café e pão ou bolacha (Tabela 3). Não há diferença significativa na qualidade dos desjejuns de parceiros e outros $(\mathrm{p}=0,462)$.

Tabela 3. Distribuição percentual da avaliação qualitativa das refeições do dia alimentar (ValinhosSP, 2006)

\begin{tabular}{cccccc}
\hline Refeição & Ausente & Completo & Incompleto & Padrão & Só café \\
\hline Desjejum & 8,86 & 1,27 & 36,71 & 15,19 & 37,97 \\
Almoço & 2,53 & 46,84 & 50,63 & - & - \\
Jantar & 2,53 & 34,18 & 63,29 & - & - \\
\hline
\end{tabular}

\section{Discussão}

Esta pesquisa integrou o projeto "Promoção da saúde, segurança alimentar e nutrição: a contribuição da educação nutricional", que comportou, além desta, mais três investigações sendo, duas no mesmo bairro, outra no município, e uma intervenção educativa desenvolvida na escola freqüentada pelas crianças das famílias pesquisadas neste estudo, em momento posterior às pesquisas. Os resultados apresentados precisam ser 
analisados na confluência com os resultados dos outros dois estudos realizados concomitantemente na mesma área. Naqueles foi empregada metodologia qualitativa, e seus resultados contribuem para ampliar a análise e interpretação dos resultados quantitativos desta pesquisa e aprofundar a compreensão sobre fatores condicionantes do consumo alimentar na comunidade e na escola. A interação de resultados quantitativos com observações provindas de estudos levados a efeito através de métodos qualitativos, possibilita analisar os fenômenos estudados por vários ângulos, caracterizando a triangulação de métodos ${ }^{15}$. Esta possibilita ao pesquisador analisar os sentidos dados aos fatos pelos sujeitos, os conflitos e as contradições, procurando uma compreensão ampliada dos fenômenos. No caso do presente estudo, além de se constatar o fato alimentar, ou seja, o consumo de alimentos, busca-se explicar esse fato a partir da subjetividade dos sujeitos.

O primeiro desses trabalhos, de autoria de Alves ${ }^{16}$, consistiu em investigação sobre o trabalho das mulheres na agricultura e na provisão da alimentação da família, tendo sido desenvolvido com uma sub-amostra de meeiros e o outro, de autoria de Voorpostel ${ }^{17}$, versou sobre as representações sobre alimentação e sobre alimentação escolar de professores e funcionários da escola rural. Desta forma, a análise e discussão serão feitas pela comparação com resultados de estudos semelhantes, e também pelo cotejamento com os resultados desses dois estudos realizados paralelamente na mesma área geográfica.

Um dos objetivos norteadores do estudo dizia respeito ao consumo de frutas face à disponibilidade local desse produto. A constatação de que $40,5 \%$ dos entrevistados consumiram fruta, mas que apenas 3,8\% consumiram duas ou mais porções é um dado bastante preocupante, considerando que essas pessoas vivem em um meio em que as frutas são abundantes. Jaime e Monteiro ${ }^{9}$, em uma amostra de 5000 pessoas, representativa da população brasileira, constataram que menos de $30,0 \%$ consomem frutas diariamente e que esse consumo era menor na zona rural do que na urbana. Um estudo realizado na Região
Metropolitana de São Paulo, por Morimoto e cols. ${ }^{18}$, com adultos, apontou que $50 \%$ dos indivíduos não consumiram frutas no dia da pesquisa e, outro, realizado no município de São Paulo, por Toral e cols. ${ }^{19}$, com adolescentes de 10 a 19 anos, constatou, em uma amostra de 234 escolares, que apenas $12,4 \%$ e $10,3 \%$ apresentavam consumo adequado de frutas e verduras respectivamente. $\mathrm{Na}$ pesquisa realizada por Toral, também foi perguntada a opinião dos entrevistados acerca de seu consumo e foi constatado que $79,7 \%$ e $83,7 \%$ acreditavam que possuíam hábitos alimentares adequados em relação ao consumo de frutas e verduras, avaliação similar à encontrada no presente estudo, em que $91,0 \%$ e $85,0 \%$ dos sujeitos referiram que costumavam consumir frutas e verduras freqüentemente. Esses resultados evidenciam uma contradição entre os fatos resgatados pela memória em relação ao ocorrido nas últimas $24 \mathrm{~h}$ e aquilo que é declarado como prática usual, ao se questionar a freqüencia de consumo. Talvez a resposta dada neste segundo caso se aproxime mais da representação sobre o próprio consumo, influenciada por conceitos sobre o que se considera que seria correto fazer ou, pelo menos, responder, enquanto o recordatório revela com mais fidedignidade, o que a pessoa de fato fez.

Por outro lado, no estudo realizado por Alves ${ }^{16}$, foi observado que frutas da produção para venda, especialmente a goiaba, eram consumidas pelos agricultores durante $o$ trabalho, "para enganar o estômago", ingestão esta não mencionada no R24h, o que sugere que o consumo de frutas avaliado por meio desta técnica pode ser subestimado porque alimentos ingeridos durante o trabalho não são espontaneamente mencionados no relatado. A execução simultânea do presente estudo e de outro empregando metodologia qualitativa, permitiu constatar esse fato e apreender as razões que podem explicar o baixo consumo de frutas em zona rural. Para esta comunidade, a fruta está mais ligada à esfera do trabalho com a lavoura do que aos conceitos simbólicos que a aproximariam da idéia de "comida". O consumo durante o trabalho parece ocorrer em virtude da presença 
simultânea de três fatores que o favorecem: a fome, a falta de possibilidade de buscar outro alimento e o custo zero, condicionantes apontados por $\mathrm{Brug}^{4}$ para o consumo de FVL, na situação em que o ato de consumir é uma reação à situação e não procede do desejo de consumir o alimento, ou da decisão consciente de obtê-lo.

Além do fato das frutas não serem categorizadas pelos sujeitos como "alimento", por serem destinadas à comercialização, não eram de consumo livre pelos parceiros, tendo sido observado constrangimento em relação à prestação dessa informação, pois se afirmassem ter consumido frutas da plantação, isso se configuraria como roubo de mercadoria que lhes pertencia apenas parcialmente. Tais constatações confirmam a observação de Garcia $^{20}$, que, ao discutir a influência das representações sociais sobre dados de inquéritos alimentares, diz que informações sobre alimentação oscilam entre objetividade e subjetividade porque constituem parte da vida social e afetiva, sofrendo influência das representações que os entrevistados têm sobre o objeto da pesquisa, o que faz de seus relatos uma interpretação dos fatos e não exatamente seu retrato.

Em relação às preferências, em estudo realizado no Município de Piracicaba ${ }^{21}$, foi observado que a alface era a hortaliça preferida dos escolares (95,5\%), segundo informação prestada pelos pais, seguida pela rúcula $(44,7 \%)$, couve $(42,4 \%)$ e pelo tomate $(41,7 \%)$. Quando a mesma pergunta foi feita aos escolares, a alface foi citada em primeiro lugar por $93,8 \%$ dos alunos e o tomate veio logo após, citado por $63,3 \%$ deles. Em Valinhos, o tomate foi o primeiro legume mais consumido, precedendo a alface. As hortaliças mais apreciadas não são exatamente aquelas de mais fácil produção no sítio onde a família reside. O tomate, apesar de ser sempre comprado, é a hortaliça mais presente nas refeições, não sendo, portanto, o fator econômico decisivo na seleção do que consumir, mas sim a preferência.

A razão do baixo consumo de FVL não se relaciona apenas à condição econômica e disponibilidade. A grande maioria dos entrevistados afirmou que esses alimentos faziam parte da sua alimentação e observou-se que freqüentemente ocorrem doações de FVL entre vizinhos. Esses alimentos não são rejeitados, entretanto, verduras e legumes demandam tempo para o preparo (à exceção do tomate), devem ser saboreados e, portanto, consumidos em momentos especiais ${ }^{16}$, motivo pelo qual não integram a alimentação cotidiana, que visa estritamente a saciedade ${ }^{22}$. Para saciar a fome e garantir a vitalidade do corpo para o trabalho, arroz com feijão e um pedaço pequeno de carne são considerados suficientes. $\mathrm{O}$ estudo de Voorpostel ${ }^{17}$ possibilitou perceber que a idéia de que FVL são alimentos "fracos" existe também entre os professores da escola, que consideram que a merenda escolar deve ser constituída por arroz, feijão e carne, por serem alimentos que "sustentam". Embora os professores concordem com o fato de que FVL são saudáveis, eles consideram que não são alimentos adequados àqueles alunos. Há, portanto, consonância entre as representações das famílias e dos professores da escola, acerca do valor dos alimentos e da necessidade ou não de consumi-los.

Essas representações sobre o consumo de FVL revelam os nós críticos do comportamento alimentar, porque constituem fatores preditores do consumo ${ }^{4}$, relevantes ao planejamento de intervenções educativas. Os fatores condicionantes do consumo alimentar são vários e de diferentes naturezas: disponibilidade, acesso, renda, fome e sede, familiaridade, normas culturais e sociais, conhecimento e intencionalidade. No espaço onde as pessoas vivem e se alimentam, esses fatores atuam como condicionantes físicos e sociais, de tal forma que o comportamento alimentar resulta da interação entre eles. As famílias consideram que consomem FVL, os professores sabem da importância de se consumir FVL, entretanto, assim como a própria comunidade, eles consideram que para aquelas famílias, esses alimentos não são prioritários, porque eles devem receber alimentos "que sustentam", expressão que ocupa posição central no discurso sobre a qualidade da alimentação.

O ritmo de trabalho é um outro fator explicativo do baixo consumo, pois as 
mulheres saem cedo de casa para trabalhar na roça e dispõem de pouco tempo para preparar a refeição para a família, havendo dificuldade de conciliação entre atividades domésticas e trabalho na agricultura ${ }^{16}$. Como as famílias estudadas eram mais numerosas do que são as de zona urbana, e o preparo de hortaliças demanda um trabalho adicional, diretamente proporcional ao número de pessoas que participa das refeições, a densidade familiar funciona como fator adverso ao consumo, fato também observado por Figueiredo ${ }^{23}$.

Em relação ao fator econômico, cabe mencionar que as famílias não se consideram pobres, mas "remediadas", fato observado por Alves ${ }^{16}$ e por Bombardi ${ }^{24}$ que também realizou pesquisa na mesma área. Decorre daí que a ausência de um alimento considerado pouco importante para preparar o corpo para o trabalho, como é o caso de FVL, não se apresenta como problema, pois não se deve à falta de recurso para adquiri-lo, mas a uma contingência da própria vida, com pouco tempo para o preparo das refeições e grande número de pessoas na família.

O trabalho na terra é muitas vezes um fator adverso e não favorável ao consumo de hortaliças. O fato das famílias terem uma permanência transitória nos sítios, uma vez que se mudam frequientemente, também é um fator explicativo para o desinteresse pelo plantio e cultivo desses alimentos. O fenômeno da mobilidade e impermanência na terra foi observado por Candido ${ }^{25}$, em estudo sócio-antropológico, realizado no interior paulista nas décadas de cinqüenta e sessenta. A esse respeito observa o autor que a precariedade de direitos leva à incerteza e esta à repulsa por um trabalho do qual não se tem certeza do retorno.

A idéia de que o acesso a terra é condição suficiente para justificar o incentivo ao plantio e consumo, assim como a orientação para se fazer hortas domésticas em terrenos onde há espaço para isso visando aumentar a disponibilidade de hortaliças, não se sustenta frente aos resultados do estudo. A falta de tempo, as restrições impostas pelos patrões, as mudanças freqüentes, as representações sobre FVL, o número de pessoas na família são fatores que explicam a falta de exploração da terra para autoconsumo, assim como o baixo consumo.

Em contrapartida, há fatores facilitadores do consumo de FVL, como a doação de alimentos entre vizinhos e disponibilidade de frutas ao alcance das mãos para saciar a fome ("enganar o estômago") no período em que os agricultores estão trabalhando na roça.

Uma implicação desses resultados para as ações de promoção da alimentação saudável é a inadequação de se abordar concomitantemente FVL. Esta dúvida, já levantada por $\mathrm{Brug}^{4}$, parece pertinente, uma vez que os determinantes do consumo de hortaliças são diferentes daqueles relativos ao consumo de frutas. Momentos e formas considerados adequados ao consumo desses alimentos divergem, a despeito de sua similaridade nutricional. Se por um lado eles têm muito em comum no que concerne às propriedades nutricionais, do ponto de vista de consumo, eles são bastante diferentes, e as ações de incentivo devem ser condizentes com os usos e costumes.

Voorpostel $^{17}$ observou que os professores da escola têm uma representação sobre a condição alimentar das crianças que não corresponde ao encontrado neste estudo. Para eles, as crianças são extremamente pobres e "passam fome", necessitando receber, na escola, arroz, feijão e carne. O principal obstáculo à participação desses professores no incentivo ao consumo de FVL não é, portanto, a falta de conhecimentos sobre nutrição, mas suas representações sobre as condições de vida e necessidades dos alunos. A fartura de frutas não é resgatada pelos educadores como um recurso para atividades de educação nutricional, assim como também o trabalho na terra não é prestigiado, pois, para eles o objetivo do estudo é dar condições aos alunos de deixar a vida de agricultor.

\section{Conclusões e Recomendações}

O consumo de FVL é baixo, mas as famílias consideram que esses alimentos fazem parte de seu padrão de consumo habitual e que não necessitam deles em maior 
quantidade. A contradição entre o que se pensa e se diz que faz (práticas declaradas) e o que realmente se faz (práticas observadas e reconstruídas) é um importante aspecto a ser explorado nos programas educativos.

$\mathrm{O}$ acesso à terra não é um fator que, por si só, influencie positivamente a alimentação, porque no regime de meação ou parceria, o tempo despendido no cultivo da horta e no preparo de alimentos, compete com o tempo de trabalho na lavoura, este sim possuidor de valor econômico. Além disso, os proprietários da terra não incentivam os meeiros a produzir para auto-consumo.

O consumo de frutas é favorecido pela disponibilidade delas durante o período de trabalho na lavoura, mas este consumo não é relatado no R24h, podendo estar subestimado em inquéritos alimentares. $\mathrm{O}$ consumo de FVL é favorecido também por trocas entre vizinhos, comportamento que poderia ser incentivado em ações educativas, reforçando um traço de solidariedade já existente na comunidade.
As atividades de educação alimentar e nutricional na comunidade não podem passar ao largo dos significados dos alimentos e dos conhecimentos e representações sobre alimentação. O desvelamento da realidade em que vivem as famílias e na qual trabalham os professores possibilita a formulação de programas com conteúdos significativos, alinhados com a realidade cotidiana da população, com sua cultura e voltado à superação das adversidades, isto é, emancipatórios.

A apreensão das representações e valores que dão sustentação ao fato alimentar possibilita conceber programas que abordem e discutam condicionantes objetivos e subjetivos da alimentação, contribuindo para a remoção de barreiras limitantes da qualidade de vida, da emancipação e do aumento do controle sobre a vida, porque a aprendizagem efetivamente acontece quando o conteúdo é significativo para o projeto de vida da pessoa.

\section{Agradecimentos}

As autoras agradecem ao CNPq pelo apoio financeiro (processo 402078/2005-5 Pesquisa Individual) e, ao Núcleo de Estudos e Pesquisas em Alimentação - NEPA/UNICAMP, o apoio logístico à realização da pesquisa.

\section{Referências Bibliográficas}

1. Organización Mundial de la Salud. 57 . Assembléia Mundial de la Salud. Estratégia mundial sobre régimen alimentario, actividad física y salud. Ginebra: Organización Mundial de la Salud, 2004.

2. Carvalho SR. Os múltiplos sentidos da categoria "empowerment" no projeto de promoção à saúde. Cad. Saúde Pública. 2004; 20 (4): 1088-1095.

3. Braga, V. Cultura alimentar: contribuições da antropologia da alimentação. Saúde em revista. 2004; 6 (13): 37-44.

4. Brug J, Vet E, Nooijer J, Verplanken B. Predicting fruit consumption: cognitions, intention and habits. J Nutr Educ Behav. 2006; 38 (2): 73-81.
5. Granner ML, Sargent RG, Calderon KS, Hussey JR, Evans AE, Watkins KW. Factors of fruit and vegetable intake by race, gender, and age among young adolescents. J Nutr Educ Behav. 2004; 36 (4): 173-180.

6. Monge-Rojas R, Garita C, Sanchez M, Muñoz L. Barriers to and motivators for healthful eating as perceived by rural and urban Costa Rican adolescents. J Nutr Educ Behav. 2005; 37 (1): 33-40.

7. Barretto SAJ, Cyrillo DC. Análise da composição dos gastos com a alimentação no Município de São Paulo (Brasil) na década de 1990. Rev Saúde Pública. 2001; 35 (1):52-9.

8. Jaime PC, Monteiro CA. Fruit and vegetable intake by Brazilian adults. Cad. Saúde Pública. 2005; 21 Supl: S19-S24.

9. Levy-Costa RB, Sichieri R, Pontes NS, Monteiro CA. Disponibilidade domiciliar de 
alimentos no Brasil: distribuição e evolução (1974-2003). Rev Saúde Pública. 2005; 39 (4): 530-540.

10. Aranceta J. Nutrición comunitária. ALAN 2004; 54 (Supl 1): 9-13.

11. Serra-Majem L. Las mejores prácticas en nutrición comunitaria: retos y compromisos. ALAN. 2004; 54 (Supl 1): 40-43.

12. Poulain JP, Proença RPC. Reflexões metodológicas para o estudo das práticas alimentares. Rev. Nutr. 2003;16 (4):365- 386. 13. Alves HJ, Boog MCF. Comportamento alimentar em moradia estudantil: um espaço para promoção da saúde. Rev Saúde Pública. 2007; 41(2): 197-204.

14. Intituto Brasileito de Geografia e Estatística. Pesquisa Nacional por Amostra de Domicílios. [Citado em 2008 ago 8]. Disponível em: http://www.ibge.gov.br/home/estatistica/popul acao/trabalhoerendimento/pnad2006/tabsintes e.shtm.

15. Minayo MCS. Introdução: conceito de avaliação por triangulação de métodos. In: Avaliação por triangulação de métodos. Rio de Janeiro: Fiocruz; 2005.

16. Alves HJ. Práticas e representações sobre alimentação e saúde entre fruticultores da zona rural de Valinhos-SP. [Dissertação de Mestrado]. Campinas: Universidade Estadual de Campinas, 2007.

17. Voorpostel CR. Percepções de professores e funcionários de escola rural sobre a alimentação. [Dissertação de Mestrado]
Campinas: Universidade Estadual de Campinas; 2007.

18. Morimoto JM, Latorre MRDO, César CLG, Carandina R, Barros MBA, Goldbaum $\mathrm{M}$ et al. Fatores associados à qualidade da dieta de adultos residente na Região Metropolitana de São Paulo, Brasil. Cad. Saúde Pública. 2008; 24 (1): 169-178.

19. Toral N, Slater E, Cintra, IP, Fisberg M. Comportamento alimentar de adolescentes em relação ao consumo de frutas e verduras. Rev. Nutr. 2006; 19(3): 331-340.

20. Garcia RWD. Representações sobre consumo alimentar e suas implicações em inquéritos alimentares: estudo qualitativo em sujeitos submetidos à prescrição dietética. Rev. Nutr. 2004; 17 (1): 15-28.

21. Sanches M. Hortaliças: consumo e preferência de escolares. [Dissertação de Mestrado] Piracicaba: Escola Superior de Agricultura "Luiz de Queiroz", 2002.

22. Matta R. Sobre comidas e mulheres. In: O que é o Brasil? Rio de Janeiro: Rocco; 2004. p: 29-36.

23. Figueiredo ICR. Determinantes do consumo de frutas, verduras e legumes em adultos residentes no município de São Paulo. [Tese de Doutorado] São Paulo: Faculdade de Saúde Pública da Universidade de São Paulo, 2006.

24. Bombardi LM. O bairro Reforma Agrária e o processo de territorialização camponesa. São Paulo: Anablume; 2004.

25. Cândido A. Os parceiros do Rio Bonito. São Paulo: Duas Cidades; Ed 34; 2001.

\section{Autores}

Maria Cristina Faber Boog - Docente Aposentada do Departamento de Enfermagem - Faculdade de Ciências Médicas da Universidade Estadual de Campinas

Correspondência: R. Pedro Leardini, 200 - Valinhos-SP - Brasil CEP: 13.271-651

Fone: (19) 3871-3810; Fax: (19) 3869-2945

E-mail: crisboog@fcm.unicamp.br; cristinaboog@hotmail.com

Maria da Conceição Pereira da Fonseca - Instituto Multidisciplinar em Saúde "Anísio Teixeira"

Universidade Federal da Bahia

Hayda Josiane Alves - Departamento de Saúde Pública da Escola de Enfermagem Anna Nery - Universidade

Federal do Rio de Janeiro.

Cristiane Ramos Voorpostel - Pontifícia Universidade Católica de Campinas - SP

Recebido em: 16/06/2008

Aceito em: 26/08/2008 